\title{
Proposed explanations for excess injury among veterans of the Persian Gulf War and a call for greater attention from policymakers and researchers
}

\author{
N S Bell, P J Amoroso, D H Wegman, L Senier
}

\begin{abstract}
Introduction-Death rates among US veterans of the Persian Gulf War were lower than rates among non-deployed veterans and the US population at large, with the exception of injury deaths; returning veterans were at significantly greater risk of injury mortality. Similar patterns of excess injury mortality were documented among US and Australian veterans returning from Vietnam. In spite of these consistent findings little has been done to explain these associations and in particular to determine whether or not, and how, war related exposures influence injury risk among veterans returning home after deployments.

Hypothesized pathways-Several potential pathways are proposed through which injury might be related to deployment. First, increases in injury mortality may be a consequence of depression, posttraumatic stress disorder, and symptoms of other psychiatric conditions developed after the war. Second, physical and psychological traumas experienced during the war may result in the postwar adoption of "coping" behaviors that also increase injury risk (for example, heavy drinking). Third, greater injury risk may be the indirect consequence of increased experiences of ill defined diseases and symptoms reported by many returning veterans. Fourth, veterans may experience poorer survivability for a given injury event resulting in greater mortality but not morbidity. Finally, the process that selects certain individuals for deployment may lead to a spurious association between deployment status and injury mortality by preferentially selecting individuals who are risk takers and/or exposed to greater hazards.

Conclusions-More research and attention from policymakers is needed to clarify the link between deployment and postwar increased risk of injury.

(Injury Prevention 2001;7:4-9)
\end{abstract}

Keywords: military personnel; veterans; wounds and injuries; Gulf War
In 1990, the US and her military partners initiated a combined force against Iraq during Operation Desert Shield/Desert Storm (ODS/ DS). Shortly after the war, participating soldiers began to report high rates of chronic, unexplained illnesses, which they believed might have been related to their service in the Gulf. $^{1-8}$ There has now been more than a decade of extensive public debate, congressional hearings, clinical evaluations, and research culminating in the expenditure of approximately one billion dollars (US) (LTC James R Riddle, US Air Force, Office of the Assistant Secretary of Defense, Clinical and Program Policy, Pentagon, oral communication, 13 January 2000). In the aftermath of this impressive effort, however, non-battle injury remains the only documented cause of increased postwar mortality among the soldiers who fought in the Gulf. ${ }^{9-11}$ Even during ODS/DS unintentional non-battle injuries were a more common cause of fatality than battle related injuries or illnesses. ${ }^{12} 13$ However, the etiology of this increased risk for injury fatality has not been evaluated; nor have effective intervention strategies been identified.

Little information has been published regarding non-fatal injury among deployed veterans of ODS/DS. We do know that non-fatal unintentional injuries and musculoskeletal conditions (which are often related to "old" injuries) comprised the single greatest category of outpatient visits during the war, caused the largest number of days lost from duty, and was the most common reason for evacuation from the Gulf. ${ }^{13}{ }^{14}$ A 1996 report found a slight, non-significant increase in risk of postwar injury hospitalization among deployed veterans as compared to non-deployed veterans. ${ }^{15} \mathrm{~A}$ more recent study that links active duty records to civilian and Veteran's Administration data also suggests postdeployment excess injury morbidity risk. ${ }^{16}$ Given that deployed veterans are at greater risk of fatal injury it seems likely that injury morbidity will also be greater. But because there have been so few studies investigating injury morbidity among ODS/DS veterans, we do not know how the frequency or severity of injuries differ for deployed US 


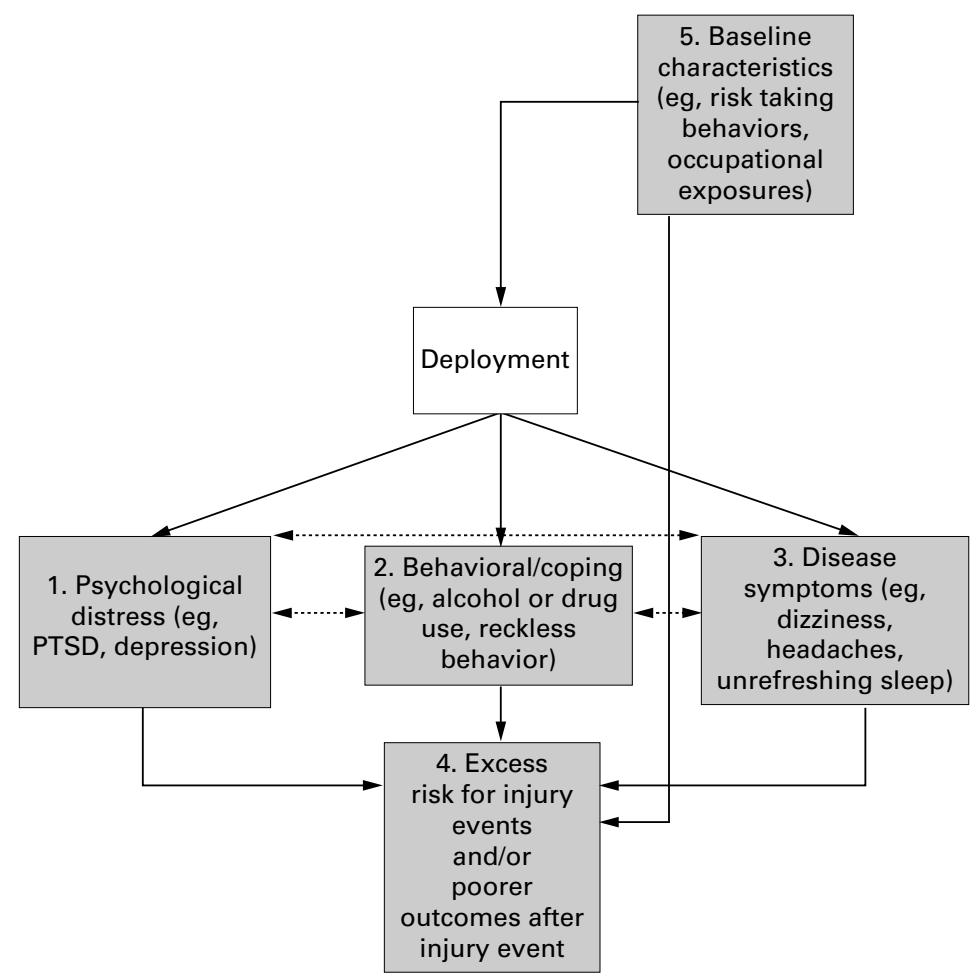

Figure 1 Potential explanations for the association between deployment and injuries (PTSD $=$ post-traumatic stress disorder).

veterans. Even less is known about possible increases in injury morbidity among US military allied forces.

The link between deployment to war zones and subsequent increases in non-battle injuries is not unique to ODS/DS. Symptoms and health outcomes commonly reported by veterans of ODS/DS, including injuries, are similar to those reported by veterans of other conflicts. ${ }^{17}$ For example, US veterans of the Vietnam conflict also experienced greater risk for injuries resulting from motor vehicle crashes, poisonings, fires and burns, homicide, and suicide after returning home. ${ }^{18-26}$ An Australian study found that injury accounted for $74 \%$ of the postwar mortality among their soldiers who served in Vietnam. ${ }^{27}$

As with ODS/DS, attention from the media, policymakers, and researchers on the problems of Vietnam veterans focused almost exclusively on health outcomes other than the observed increased risk of injury mortality. Indeed, many of the mortality studies among Vietnam veterans were initiated in response to concerns from veterans about a possible relationship between exposure to herbicides and increases in cancer risk, and found the excess risk of injury serendipitously. ${ }^{18-21} 2328$

\section{Hypothesized explanations for excess injury}

There are several ways in which deployment to a hostile environment may directly or indirectly increase risk of injury after redeployment. Figure 1 details five possible pathways, with references to known factors that support their theoretical basis.
(1) Higher rates of injury mortality may be a consequence of increases in clinical depression, post-traumatic stress disorder (PTSD), or other psychiatric conditions subsequent to service in the Gulf. ${ }^{9}$ Such conditions have been documented among US, British, and Danish veterans of the Gulf War. ${ }^{5-89-37}$ Studies have documented a link between conditions such as depression and PTSD, and subsequent risk for self inflicted injury. ${ }^{38-47}$ Suicide risk and PTSD were greatest among Vietnam veterans who had been wounded during battle and/or had experienced psychological trauma while in Vietnam. ${ }^{24-26}$ These states may also lead to increased risk for unintentional injuries. Depression, for example, may slow response time, and is associated with alcohol use. The association between alcohol use and injuries has been well documented in the literature. Comorbidities of depression and alcoholism are known to increase risk for suicide. ${ }^{48} 49$

(2) The physical and psychological traumas experienced during war may result in the postwar adoption of potentially unhealthy "coping behaviors". Several studies have documented an association between exposures to emotional or physical trauma and increased use of alcohol or other substances. ${ }^{50-54}$ Indeed, the military may, on occasion, inadvertently support the use of alcohol for coping with stress. At a recent conference on operational stress, one commander related a story of how his unit was withdrawn from their deployment to a "neutral" location before returning to their families, and spoke frankly about the role the beer tent played as a tool for deployment related stress relief. ${ }^{55}$ Changes in behavior may occur independent of any diagnosed mental illness or condition, yet still be an indirect consequence of an experience occurring in the Persian Gulf. For example, perceived near-death experiences have been shown to result in profound changes in values, beliefs, and behaviors as they relate to living and dying. ${ }^{56-58}$ Such changes might result in more reckless behavior and less regard for personal safety.

(3) Increased risk of injury may be the indirect consequence of the ill defined diseases and symptoms reported by many veterans, including fibromyalgia, chronic fatigue syndrome, and symptoms such as dizziness, shakes or tremors, unrefreshing sleep, fatigue, muscle and joint pain, and confusion..$^{239-66}$ Whether or not these conditions are a direct consequence of service in the Gulf they are frequently reported by veterans of ODS/DS and may result in reduced response time or an inability to safely negotiate out of a hazardous situation (for example, motor vehicle collision avoidance). Alternatively or concurrently, a veteran suffering from these conditions might be more likely to make decisions that may increase exposures to hazardous circumstances. For example, they may be more inclined to enter a quarrel, which could escalate to interpersonal violence. Thus far, the documented association between service in the Gulf and increased injury mortality has not been evaluated to determine if certain subgroups (for example, those suffering from 
multisymptom illnesses) are responsible for the observed differences in injury risk.

(4) Kang and Bullman report only an excess of injury mortality. ${ }^{9}$ One recent study provides some information about non-fatal injuries suggesting that deployed veterans may be at increased risk for injury hospitalizations. However, the findings were not consistent across all types of hospital settings. ${ }^{16}$ Without an understanding of the prevalence of non-fatal injury among deployed and non-deployed Gulf War era veterans it is impossible to ascertain whether or not veterans are at increased risk for injury events or whether they are at increased risk for death (or poorer outcomes in general) once they experience a given type of injury (for example, motor vehicle crash related injury). Psychological distress, coping behavioral responses, and illness symptoms may act as modifiers of an injury event. A veteran of ODS/DS who incurs a postwar injury may be more likely to experience adverse sequelae than an injured veteran who was not deployed to the Gulf, due to the presence of war related comorbidities.

(5) A final possible explanation for excess injury morbidity lies in the potential for bias related to selecting individuals for deployment who are inherently at greater injury risk. This increased injury risk may stem from a number of baseline personality or occupational characteristics such as: belonging to an occupational group with documented hazards (for example, vehicle drivers), risk taking or other behaviors (for example, speeding, smoking, alcohol consumption). These factors could increase risk of experiencing an injury event and/or result in a poorer outcome after the event (for example, smokers are more likely to experience stress fractures, and take longer to heal than non-smokers). ${ }^{67} 68$

There is little baseline information available that would allow exploration of prewar and postwar risk taking habits and injury predisposition among Gulf War era veterans. It is plausible, however, that the same factors that make a soldier a likely candidate for deployment may also be associated with greater risk of injury independent of the war. Soldiers who are sensation seekers or risk takers may be more inclined to self select to serve in the Gulf or to be employed in occupational specialties with a higher likelihood of deployment (for example, Infantry, Airborne, Rangers, and Special Forces). Our investigation demonstrates that soldiers who received special hazardous duty pay for activities such as parachuting or exposure to enemy fire in the period well before the start of ODS/DS were the same ones most likely to be deployed to the Persian Gulf, even after controlling for occupation. ${ }^{69}$ Bricknell et al have also documented increased injuries among Army infantry who collect hazardousduty pay as compared to infantry who do not collect this special pay. ${ }^{70}$

Increased injury frequency or severity may stem from any one of these five proposed explanations, some combination of them, or some other yet undiscovered pathway. In any case, injuries need to be further studied. This requires more support and attention from policymakers and researchers alike.

\section{Barriers to the study of deployment related injuries}

Despite evidence for the association between military deployment and excess injury, most research has focused on the search for a unifying case definition of "Gulf War illnesses," and a search for an etiologic pathway, or several pathways, to explain the myriad of symptoms and conditions reported by veterans of ODS/ DS. While the importance of these chronic multisymptom illnesses and the disability and suffering experienced by veterans must not be trivialized, the lack of attention paid to the risk factors that contribute to raised injury mortality, and to designing and implementing interventions to reduce injury in this group of veterans, is puzzling.

One of our top research priorities should be the examination of the plausible hypothesis that excess rates of postwar injuries are the direct result of experiences, or the indirect result of exposures, that occurred during deployment. Other researchers and agencies have also expressed this sentiment. ${ }^{71}{ }^{72}$ To date, however, with the exception of the five studies that describe the excess risk for non-battle injury mortality, ${ }^{911-14}$ discussion and review of injury among Gulf War veterans has been limited to studies describing battle related injuries and/or their psychological sequelae. ${ }^{73-86}$ Few resources have been devoted to this issue: of the 159 million dollars spent between 1994-99 on research related to ODS/DS veterans' health, only a small proportion has gone to the study of excess injury. ${ }^{87}$ Though one study is currently being conducted to evaluate motor vehicle injuries in this population, ${ }^{88}$ we are not aware of any projects underway at this time that will clarify the specific etiologic pathways leading to increased injury mortality among deployed veterans. While there has been some effort to increase the study of injury etiology and prevention in the military at large, ironically the relationship between deployment to war and peacekeeping missions, and the non-battle injuries that occur during and after deployments, are not receiving appropriate emphasis. ${ }^{13990}$

A thorough examination of the relationship between deployment and injuries is undoubtedly hampered by the misperception that injuries are the end result of random, uncontrollable events. This is in spite of the extensive list of studies that have demonstrated time and again how well designed interventions have reduced injury rates in both civilian and military settings. ${ }^{91}{ }^{92}$ The Navy, for example, has succeeded in reducing class $\mathrm{A}$ aviation crashes from 55/100 000 flying hours to only $3 / 100000$ flying hours over the past 50 years. ${ }^{89}$ This impressive decline in loss of life and property has been accomplished through engineering changes (for example, the angling of aircraft carrier decks) and persistent systematic application of training and safety initiatives. ${ }^{93}$ 
A related explanation for the relative lack of attention to injury mortality is that veterans who suffer from ill defined conditions and symptoms have lobbied for research devoted to finding a cure or improved treatment for ailing veterans. By contrast, families of veterans killed in motor vehicle crashes or other injury events, veterans' advocacy groups, or even injured veterans themselves may not lobby for increased research into injury prevention if they too subscribe to the misconception that injuries are the end result of random events. Likewise, self inflicted injuries may appear to have no external cause at all, as blame is often mistakenly placed solely on the individual.

The link between deployment and injury may also not be readily identified in part due to the way injury is usually treated. In a clinical setting, acute trauma is managed almost entirely in emergency departments and acute care clinics where there may be little continuity of care and therefore no discovery or cause for investigation of a potential common pathway. Physicians treating victims of acute trauma need to broaden their understanding of the risk factors that might predispose a patient to injury to include deployment related conditions.

\section{Recommendations for future studies}

The US military has made significant progress in recent years in recognizing the extent and severity of the injury problem across all branches of the armed forces. There is now a large corps of researchers who are studying costs and the impact injuries have on the mission and readiness of the military. Three important publications have emerged in the past few years documenting the epidemiologic evidence that has come to light as a result of these efforts. ${ }^{94}$ These efforts are laudable, and demonstrate that the military is moving in the right direction by recognizing and documenting the extent of the problem, and putting programs in place that will likely reduce injury. However, what is lacking is a comprehensive research program to explore the causes and prevention alternatives for the specific deployment related injury excesses that have been consistently identified. A concerted effort is essential if we are to determine the etiology of increased injury risk among this special subgroup of deployed soldiers, whose risks are unlikely to be identified through the existing efforts and who will very likely require specially tailored intervention efforts.

Those interested in exploring the link between deployment and non-battle injuries, and in designing prevention programs, need better information about the reasons for the observed increased injury risk among veterans. The following appear to be important steps in this effort: document the incidence of non-fatal injury among deployed and non-deployed veterans both in the US and abroad; explore the role of risk taking behaviors before and after deployment; determine whether there are subpopulations at unique or particular risk for behavior changes; identify potential modifying factors that protect individuals from injury or

\section{Key points}

- Death rates among US veterans were lower than rates among non-deployed veterans and the US population at large, with the exception of injury deaths; deployed veterans were at significantly greater risk of injury mortality after the war.

- We propose several pathways through which risk of injury might be related to deployment:

(1) Increases in postwar injury mortality may be a consequence of depression, PTSD, and symptoms of other psychiatric conditions developed after the war.

(2) Physical and psychological traumas experienced during the war may result in the postwar adoption of "coping" behaviors that also increase injury risk (for example, heavy drinking).

(3) Greater injury risk may be the indirect consequence of ill defined diseases and symptoms (for example, fatigue, concentration difficulties) reported by many deployed veterans.

(4) Veterans may experience poorer survivability for a given injury event resulting in greater mortality but not morbidity.

(5) The process that selects certain individuals for deployment may lead to a spurious association between deployment status and injury mortality by preferentially selecting individuals who are risk takers and/or exposed to greater hazards.

- A similar pattern of increased postwar injury mortality was observed after the Vietnam War. More research and attention from policy makers is needed to clarify the link between deployment and postwar increased risk of injury.

from suffering poor outcomes after injury; identify associations between postdeployment mental health and injury; and evaluate the association between injuries and the symptom based conditions historically experienced by ODS/DS veterans. Longitudinal data sources that include measures of behavior before and after ODS/DS, though hard to come by, would be particularly useful. Focus groups or similar qualitative assessment tools may also provide important insights into risk taking habits and changes in safety related behaviors among redeploying service members.

Since injuries are more easily identified and measured than multisymptom illnesses, research into risk factors and effect modifiers may be quite cost effective and result in more immediate health improvements for veterans of the Gulf War as well as those deployed in future conflicts and peacekeeping missions. These efforts are also likely to result in significant cost savings to the federal government. There are currently more than 2.2 million people receiving disability compensation from the Veteran's Administration, about a third of whom have 
musculoskeletal system disabilities and receive direct payments of well over four billion dollars per year. ${ }^{95}$ The vast majority of disability discharges due to musculoskeletal conditions are the end result of injuries that occurred while in the military. ${ }^{96}$

Before successful interventions can be planned we need well designed studies to clarify the etiology of excess injury. This will not happen with a restrictive focus on chronic multisymptom illnesses to the exclusion of injuries. Non-battle injury must be seen as a condition potentially related to deployment. There must be high level support for injury research in this population, a re-evaluation of the current research agenda, and a reprioritization of related activities.

This effort was supported by a grant from the US Army Medical Research Acquisition Activity (USAMRAA), grant number cal Research Acquisition Activity (USAMRAA), grant number DAMD17-98-1-8610, and from the National Institute

The contents herein are the sole responsibility of the author The contents herein are the sole responsibility of the authors
and do not necessarily represent the position or the policy of and do not necessarily represent the position or the policy of NIAAA, the USAMRAA, the US Army, or the Depart
Defense. No official endorsement should be inferred.

1 Fukuda K, Nisenbaum R, Stewart G, et al. Chronic multisymptom illness affecting Air Force veterans of the Gulf War. FAMA 1998;280:981-8

2 Roy MJ, Koslowe PA, Kroenke K, et al. Signs, symptoms, and ill-defined conditions in Persian Gulf War veterans: findings from the Comprehensive Clinical Evaluation Program. Psychosom Med 1998:60:663-8.

3 Haley RW, Kurt TL, Hom J. Is there a Gulf War syndrome? Searching for syndromes by factor analysis of symptoms. fAMA 1997;277:215-22.

4 Presidential Advisory Committee on Gulf War Veterans' Illnesses. Final report. Washington, DC: US Government Printing Office, December 1996.

5 Ismail K, Everitt B, Blatchley N, et al. Is there a Gulf War syndrome? (see comments). Lancet 1999;353:179-82.

6 Ishoy T, Guldager B, Appleyard M, et al. [Health status after serving in the Gulf war area. The Danish Gulf War Study]. Ugeskr Laeger 1999;161:5423-8.

7 Ishoy T, Suadicani P, Guldager B, et al. State of health after deployment in the Persian Gulf. The Danish Gulf Wa Study. Dan Med Bull 1999;46:416-9.

8 Unwin C, Blatchley N, Coker W, et al. Health of UK servicemen who served in Persian Gulf War. Lancet 1999;353:169-78.

9 Kang HK, Bullman TA. Mortality among US veterans of the Persian Gulf War. N Engl f Med 1996;335:1498-504.

10 Kang H, Bullman T. Mortality among US veterans of the Gulf War: update through December 1997. Conference on Federally Sponsored Gulf War Veterans' Illnesses ReFederally Sponsored Gulf War Veterans
search, 24 June 1999; Arlington, VA, 1999.

11 Murphy F, Browne D, Mather S, et al. Women in the Persian Gulf War: health care implications for active duty troops Gulf War: health care implications for acti
and veterans. Mil Med 1997;162:656-60.

12 Writer JV, DeFraites RF, Brundage JF. Comparative mortality among US military personnel in the Persian Gulf region and worldwide during Operations Desert Shield and Desert Storm. FAMA 1996;275:118-21.

13 Writer JV, DeFraites RF, Keep LW. Non-battle injury casualties during the Persian Gulf War and other deployments. Am $\mathcal{F}$ Prev Med 2000;18(3 suppl 1):64-70.

14 Wasserman GM, Martin BL, Hyams KC, et al. A survey of outpatient visits in a United States Army forward unit during Operation Desert Shield. Mil Med 1997;162:374-9.

15 Gray GC, Coate BD, Anderson CM, et al. The postwar hospitalization experience of US veterans of the Persian Gulf Wir. N Engl f Med 1996;335:1505-13.

16 Gray GC, Smith TC, Kang HK, et al. Are Gulf War veterans suffering war-related illnesses? Federal and civilian hospitalizations examined, June 1991 to December 1994. Am Epidemiol 2000;151:63-71.

17 Hyams KC, Wignall FS, Roswell R. War syndromes and their evaluation: from the US Civil War to the Persian Gulf War. Ann Intern Med 1996;125:398-405.

18 The Centers for Disease Control. Postservice mortality among Vietnam veterans. FAMA 1987;257:790-5

19 Bullman TA, Kang HK, Watanabe KK. Proportionate mortality among US Army Vietnam veterans who served in military region I. Am f Epidemiol 1990;132:670-4.

20 Breslin P, Kang HK, Lee Y, et al. Proportionate mortality study of US Army and US Marine Corps veterans of the Vietnam War. F Occup Med 1988;30:412-9.

21 Lawrence CE, Reilly AA, Quickenton P, et al. Mortality patterns of New York State Vietnam veterans. Am 7 Public Health 1985;75:277-9.

22 Watanabe KK, Kang HK. Military service in Vietnam and the risk of death from trauma and selected cancers. Ann Epidemiol 1995;5:407-12.
23 Watanabe KK, Kang HK, Thomas TL. Mortality among Vietnam veterans: with methodological considerations. $\mathcal{f}$ Occup Med 1991;33:780-5.

24 Card JJ. Epidemiology of PTSD in a national cohort of Vietnam veterans. $\mathcal{F}$ Clin Psychol 1987;43:6-17.

25 Bullman TA, Kang HK, Thomas TL. Posttraumatic stress disorder among Vietnam veterans on the Agent Orange Registry. A case-control analysis. Ann Epidemiol 1991;1: 505-12.

26 Bullman TA, Kang HK. The risk of suicide among wounded Vietnam veterans. Am 7 Public Health 1996;86:662-7.

27 Fett MJ, Nairn JR, Cobbin DM, et al. Mortality among Australian conscripts of the Vietnam conflict era. II. Australian conscripts of the Vietnam conflict

28 Dalager NA, Kang HK. Mortality among Army Chemical Corps Vietnam veterans. Am f Ind Med 1997;31:719-26.

29 McCarroll JE, Ursano RJ, Fullerton CS. Symptoms of PTSD following recovery of war dead: 13-15-month follow-up. Am $\mathcal{F}$ Psychiatry 1995;152:939-41.

30 McCarroll JE, Ursano RJ, Fullerton CS. Symptoms of posttraumatic stress disorder following recovery of war dead. Am f Psychiatry 1993;150:1875-7.

31 Perconte ST, Wilson AT, Pontius EB, et al. Psychological and war stress symptoms among deployed and nondeployed reservists following the Persian Gulf War. Mil Med 1993;158:516-21.

32 Stretch RH, Bliese PD, Marlowe DH, et al. Psychological health of Gulf War-era military personnel. Mil Med 1996;161:257-61.

33 Southwick SM, Morgan A, Nagy LM, et al. Trauma-related symptoms in veterans of Operation Desert Storm: preliminary report. Am f Psychiatry 1993;150:1524-8.

34 Southwick SM, Morgan CA 3rd, Darnell A, et al. Traumarelated symptoms in veterans of Operation Desert Storm: a 2-year follow-up. Am F Psychiatry 1995;152:1150-5.

35 Engel CC Jr, Ursano R, Magruder C, et al. Psychological conditions diagnosed among veterans seeking Department of Defense care for Gulf War-related health concerns. 7 Occup Environ Med 1999;41:384-92.

36 Sutker $\mathrm{PB}$, Uddo M, Brailey K, et al. War-zone trauma and stress-related symptoms in Operation Desert Shield/Storm (ODS) returnees. F Soc Issues 1993;49:33-49.

37 Sutker PB, Uddo M, Brailey K, et al. Psychological symptoms and psychiatric diagnoses in Operation Desert Storm troops serving graves registration duty. $\mathcal{F}$ Trauma Stress 1994;7:159-71.

38 Erzurum VZ, Varcellotti J. Self-inflicted burn injuries. 7 Burn Care Rehabil 1999;20(1 pt 1):22-4.

39 Ultmann MH, Geller TJ, Chilakamairi JK, et al. Multidisciplinary rehabilitation management of depression in the carbon monoxide injured patient. Pediatr Rehabil 1998;2: carbon $101-6$.

40 Cameron DR, Pegg SP, Muller M. Self-inflicted burns. Burns 1997;23:519-21.

41 Li G, Ling J, DiScala C, et al. Characteristics and outcomes of self inflicted pediatric injuries: the role of method of suicide attempt. Inj Prev 1997;3:115-9.

42 Tuohig GM, Saffle JR, Sullivan JJ, et al. Self-inflicted patient burns: suicide versus mutilation. F Burn Care Rehabil 1995; 16:429-36.

43 Minnaar GK, Schlebusch L, Levin A. A current study of parasuicide in Durban. S Afr Med F 1980;57:204-7.

44 Henriksson TG. Close range blasts toward the maxillofacial region in attempted suicide. Scand $\mathcal{F}$ Plast Reconstr Surg Hand Surg 1990;24:81-6.

45 Frierson RL, Lippmann SB. Psychiatric consultation for patients with self-inflicted gunshot wounds. Psychosomatics 1990;31:67-74.

46 Hadjiiski O, Todorov P. Suicide by self-inflicted burns. Burns 1996;22:381-3.

47 Greene KA, Dickman CA, Smith KA, et al. Self-inflicted orbital and intracranial injury with a retained foreign body, associated with psychotic depression: case report and review. Surg Neurol 1993;40:499-503.

48 Lesage AD, Boyer R, Grunberg F, et al. Suicide and mental disorders: a case-control study of young men. $A m \mathcal{F}$ Psychiatry 1994;151:1063-8.

49 Reynolds P, Eaton P. Multiple attempters of suicide presenting at an emergency department. Can $\mathcal{F}$ Psychiatry 1986;31:328-30.

50 Bozzacco V. Vulnerability and alcohol and substance abuse in spinal cord injury. Rehabil Nurs 1990;15:70-2.

51 Davis RE. Trauma and addiction experiences of African American women. West f Nurs Res 1997;19:442-60.

52 Friedman MJ, Schnurr PP, McDonagh-Coyle A. Posttraumatic stress disorder in the military veteran. Psychiatr Clin North Am 1994;17:265-77.

53 Hierholzer R, Munson J, Peabody C, et al. Clinical presentation of PTSD in World War II combat veterans. Hospital and Community Psychiatry 1992;43:816-20.

5 Sims A, Sims D. The phenomenology of post-traumatic stress disorder. A symptomatic study of 70 victims of psychological trauma. Psychopathology 1998;31:96-112.

55 Thompson M. Changing nature of stress as it relates to "Army Vision 2010," including the peacekeeping mission and roles of US Army Reserve and Army National Guard. Leaders and operational stress. Washington, DC, 2000.

56 Greyson B. Varieties of near-death experience. Psychiatry 1993;56:390-9.

57 Greyson B. The near-death experience as a focus of clinical attention. F Nerv Ment Dis 1997;185:327-34.

58 Orne RM. The meaning of survival: the early aftermath of a near-death experience. Res Nurs Health 1995;18:239-47. 
59 Committee to Review the Health Consequences of Service During the Persian Gulf War Medical Follow-up Agency (IOM). Health consequences of service during the Persian Gulf War: recommendations for research and information
Washington, DC: National Academy Press, 1996.

60 Iowa Persian Gulf Study Group. Self-reported illness and health status among Gulf War veterans. A populationbased study. $\mathscr{F} A M A$ 1997;277:238-45.

61 Kroenke K, Koslowe P, Roy M. Symptoms in 18,495 Persian Gulf War veterans. Latency of onset and lack of association with self-reported exposures. $\mathcal{F}$ Occup Environ Med 1998;40:520-8.

62 Unexplained illnesses among Desert Storm veterans. A search for causes, treatment, and cooperation. Persian Gulf Veterans Coordinating Board. Arch Intern Med 1995;155: $262-8$.

63 Joseph SC. A comprehensive clinical evaluation of 20,000 Persian Gulf War veterans. Comprehensive clinical evaluation program evaluation team. Mil Med 1997;162:149-55.

64 Office of the Undersecretary of Defense for Acquisition and Technology. Report of the Defense Science Board Task Force on Persian Gulf War health effects. Final, unclassified. WashingPersian Gulf War health effects. Final, unclassified. Washington, DC: Department of

65 Spencer PS, McCauley LA, Joos SK, et al. US Gulf Wa veterans: service periods in theater, differential exposures, and persistent unexplained illness. Portland Environmenta Hazards Research Centre. Toxicol Lett 1998;102-103:51521.

66 Roland PS, Haley RW, Yellin W, et al. Vestibular dysfunction in Gulf War syndrome. Otolaryngol Head Neck Surg 2000;122:319-29.

67 Jones JK, Triplett RG. The relationship of cigarette smoking to impaired intraoral wound healing: a review of evidence and implications for patient care. $\mathcal{F}$ Oral Maxillofac Surg 1992;50:237-9.

68 Amoroso P, Reynolds K, Barnes J, et al. Tobacco and injury: an annotated bibliography. Technical report. Natick, MA US Army Research Institute for Environmental Medicine, February 1996. (Report No TN 96-1.)

69 Bell NS, Amoroso PJ, Williams JO, et al. Demographic, physical, and mental health factors associated with deployment of US Army

70 Bricknell M, Amoroso PJ, Yore MM. What is the risk associated with being a qualified military parachutist. Occup Med 1999;49:139-45.

71 Institute of Medicine. Health consequences of service during the Persian Gulf War: recommendations for research and information systems. Report. Washington, DC: National Academy Press, 1996.

72 Persian Gulf Veterans Coordinating Board. A working plan for research on Persian Gulf veterans illnesses. Washington, DC: Department of Veterans Affairs, November 1996.

73 Bleich A, Kron S, Margalit C, et al. Israeli psychological casualties of the Persian Gulf War: characteristics, therapy, and selected issues. Isr f Med Sci 1991;27:673-6.

74 Achte K, Jarho L, Kyykka T, et al. Paranoid disorders following war brain damage. Preliminary report. Psychopafollowing war brain dam

75 Ahlberg A, Corea JR, Sadat-Ali M, et al. The scud missile disaster in Al-Khobar, Saudi Arabia, 1991: the orthopaedic experience. Injury 1994;25:97-8.

76 Bajec J, Gang RK, Lari AR. Post Gulf war explosive injuries in liberated Kuwait. Injury 1993;24:517-20.
77 Bleich A, Dycian A, Koslowsky M, et al. Psychiatric implicaions of missile attacks on a civilian population. Israeli lestions of missile attacks on a civilian population. Israeli les-
sons from the Persian Gulf War. $7 A M A$ 1992;268:613-5.

78 Bowyer GW, Stewart MP, Ryan JM. Gulf War wounds: application of the Red Cross wound classification. Injury 1993;24:597-600.

79 Brandt GT, Norwood AE, Ursano RJ, et al. Psychiatric morbidity in medical and surgical patients evacuated from the Persian Gulf War. Psychiatr Serv 1997;48:102-4.

80 Dillingham TR, Spellman NT, Braverman SE, et al. Analysis of casualties referred to Army physical medicine services during the Persian Gulf conflict. Am f Phys Med Rehabil 1993;72:214-8

81 Dillingham TR, Braverman SE, Belandres PV. Persian Gulf War amputees: injuries and rehabilitative needs. Mil Med 1994;159:635-9.

82 Reyna TM. Observations of a pediatric surgeon in the Persian Gulf War. F Pediatr Surg 1993;28:209-13.

83 Williams CS. F-16 pilot experience with combat ejections during the Persian Gulf War. Aviat Space Environ Med 1993;64(9 pt 1):845-7.

84 Helmkamp JC. United States military casualty comparison during the Persian Gulf War. F Occup Med 1994;36:609-

85 Burkle FM Jr, Newland C, Orebaugh S, et al. Emergency medicine in the Persian Gulf War-part 2. Triage methodology and lessons learned. Ann Emerg Med 1994;23:74854.

86 Humphrey JC. Casualty management: scud missile attack, Dhahran, Saudi Arabia. Mil Med 1999;164:322-6.

87 Riddle J, Hyams K, Murphy F, et al. In the borderland between health and disease following the Gulf War. Mayo Clin Proc 2000;75:777-9.

88 Research Working Group Persian Gulf Veterans Coordinating Board. Annual report to Congress. Washington, DC: Persian Gulf Veterans Coordinating Board, June 1999.

89 Jones BH, Perrotta DM, Canham-Chervak ML, et al. Injuries in the military. A review and commentary focused on prevention. Am f Prev Med 2000;18(3 suppl 1):71-84.

90 Jones BH, Hansen BC. An Armed Forces Epidemiological Board evaluation of injuries in the military. Am $\mathcal{F}$ Prev Med 2000;18(3 suppl 1):14-25.

91 Bell NS, Amoroso PJ, Baker SP, et al. Injury control part II: strategies for prevention. Natick, MA: United States Army Research Institute of Enviornmental Medicine, January 2000. (Report No TN 00-4.)

92 Amoroso PJ, Bell NS, Baker SP, et al. Injury control part I: understanding injuries in the military environment. Natick, MA: United States Army Research Institute of Environmental Medicine, January, 2000. (Report No TN 00-3.)

93 Amoroso PJ, Bell NS, Baker SP. Injury control. In: Burr RE, Pandolf K, eds. Medical aspects of deployment to harsh environments. Washington, DC: Office of the Surgeon General, US Department of the Army, and Borden Institute (in press).

94 Peake JB. Reflections on injuries in the military. The hidden epidemic. Am f Prev Med 2000;18(3 suppl 1):4-5.

95 Amoroso P, Canham M. Disabilities related to the musculoskeletal system: physical evaluation board data. Mil Med 1999;164(8 suppl):S4-66-7.

96 Amoroso PI Smith GS, Bell NS. Qualitative assessment of cause-of-injury coding in US military hospitals: NATO standardization agreement (STANAG) 2050. Am f Prev Med 2000;18(3 suppl 1):174-87. 